\title{
HIDING INFORMATION IN OPEN AUCTIONS
}

\author{
David Ettinger \\ Fabio Michelucci
}
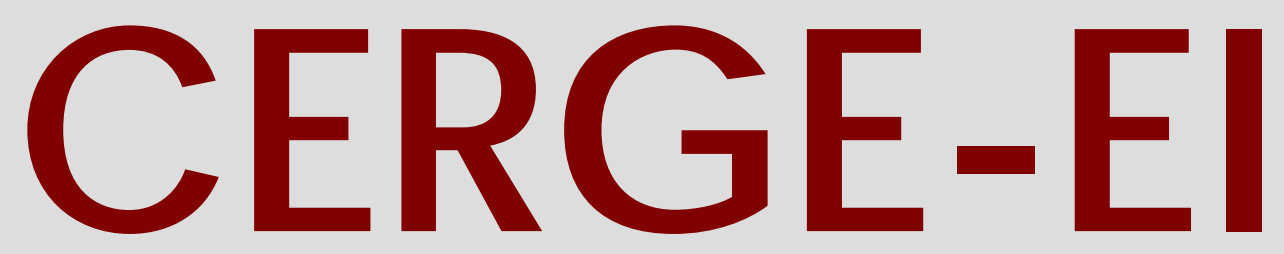

Charles University Centerfor Economic Research and Graduate Education Academy of Sciences of the Czech Republic Ec onomic s Institute 


\title{
Working Paper Series 469 (ISSN 1211-3298)
}

\section{Hiding Information in Open Auctions}

\author{
David Ettinger \\ Fabio Michelucci
}

CERGE-EI

Prague, October 2012 
ISBN 978-80-7343-273-7 (Univerzita Karlova. Centrum pro ekonomický výzkum a doktorské studium)

ISBN 978-80-7344-265-1 (Národohospodářský ústav AV ČR, v.v.i.) 


\title{
Hiding Information in Open Auctions*
}

\author{
David Ettinger ${ }^{\dagger}$ \\ Fabio Michelucci ${ }^{*}$ \\ Université Paris Dauphine, PSL* \\ CERGE-EI
}

October 23, 2012

\begin{abstract}
We analyze the rationale for hiding information in open auction formats. In particular, we focus on the incentives for a bidder to call a price higher than the highest standing one in order to prevent the remaining active bidders from aggregating more accurate information that could be gathered by observing the exact drop out values of the exiting bidders. Necessary conditions for the existence of jump bids with such motivations are provided. Finally, we show that there is no clear-cut effect of jump bids on efficiency and expected revenue and introduce several specific results.
\end{abstract}

\begin{abstract}
Abstrakt
Analyzujeme důvod pro skrývání informací ve formátech otevřených aukcí. Specificky se zaměřujeme na podněty pro dražitele k tomu, aby ohlásili částku vyšší, než je ta nejvyšší nabídnutá, aby zabránili zbývajícím aktivním dražitelům získat přesnější informace, které by mohly být získány pozorováním přesných hodnot vypadnutí existujících dražitelů. Stanovujeme nutné podmínky pro existenci skokových nabídek s touto motivací. Nakonec ukazujeme, že neexistuje jasný efekt skokových nabídek na efektivitu a očekávaný př́ijem a představujeme několik specifických výsledků.
\end{abstract}

Keywords: Auctions, Efficiency, Jump Bids.

JEL Classification: D44, D82.

\footnotetext{
*We would like to thank Levent Celik, Francoise Forges, Philippe Jehiel and Jakub Steiner for helpful discussions and feedback on earlier drafts of this paper.

${ }^{\dagger}$ PSL*, Leda, CEREMADE, Université Paris Dauphine. Place du Maréchal de Lattre de Tassigny 75775 Paris Cedex 16 France, david.ettinger.fr@gmail.com

${ }^{*}$ Fabio Michelucci, CERGE-EI, P.O. Box 882 Politickych veznu 711121 Praha 1 Czech Republic.

Email: fabio.michelucci@cerge-ei.cz.

CERGE-EI is a joint workplace of the Center for Economic Research and Graduate Education, Charles University, and the Economics Institute of the Academy of Sciences of the Czech Republic.
} 


\section{Introduction}

One of the main characteristics of an open ascending auction format is that it allows participants to aggregate new information on top of the information available ex-ante. This is also the key feature that leads auction theorists and designers to advocate, in some environments, in favor of the use of an open auction as opposed to a sealed bid auction. Surprisingly, the existing literature ignores that the participants in the auction might have an incentive to manipulate the quality (precision) of the new information that can be aggregated. We explore this issue showing that jump bids can be used to achieve such objective.

This interest in jump bids is not uniquely explained by theoretical motivations. As a matter of fact, it is a well documented fact (see Cassady (1967), Fishman (1988), Cramton (1997)) that jump bids are quite prevalent in several auction contexts although they may be perceived as a missed opportunity to win the auction for a lower price without a clear profit to counterbalance it. We intend to provide a new explanation for the existence of jump bids based on the idea of information manipulation.

In general, the new information that bidders can gather during the auction may be of different characteristics: exogenous or endogenous, private to a bidder or available to some subset of the bidders, free or costly to acquire. Here we focus on the information that can be gathered simply by observing who is active and who is not at any given price. This information is endogenous, publicly available to all active bidders, and free. In an interdependent value setting, its knowledge affects bidders' expected valuations for the object and thus it is crucial in determining their bidding behavior. We provide a rich variety of frameworks in which jump bids are used in equilibrium to manipulate the aggregation of the new information, and show that their impact on revenue and efficiency can be drastic. The same framework can be used to show that the seller can set a reserve price to prevent the aggregation of information that would lower the expected price at which the object is allocated.

For the sake of illustration, let us consider the following example. Suppose that the right to exclusively distribute a new product is for sale. Firms 1 and 2 have an 
informational advantage regarding the expected market size of the new product in their areas ( 1 and 2 , respectively). ${ }^{1}$ Firm 3 is a big foreign distributor interested in expanding its presence over the joint areas 1 and 2 . If the expected size of both market 1 and 2 is large enough, then Firm 3 has the highest valuation of the exclusive distribution rights. Conversely, if only one of the two markets is large enough, the cost to enter the new market is too big for Firm 3 and one of the other two firms holds the highest valuation. In this setting, one of the two local firms, say Firm 1, has an incentive to place a jump bid to hide the exact drop out price of Firm 2 when she ${ }^{2}$ values the exclusivity high. In fact, if Firm 2 does not match the jump bid, only the coarser information that Firm 2 valuation is between the price from which the jump bid was called and the jump bid value becomes available, leaving Firm 3 uncertain regarding whether she is the firm holding the highest valuation. The jump bid depresses the bid of Firm 3 when Firm 2's valuation is close to the value of the jump bid. The cost associated with the jump bid is that if Firm 2's valuation is close to the price from which the jump bid was called, then Firm 3 would have dropped out at a value lower than the jump bid.

Only when the benefits of providing coarser information outweigh the costs, a jump bid is placed in equilibrium. It is easy to identify trivial cases when this is the case. In the example above, for instance, it suffices to have an additional bidder whose value is known to be sufficiently high so that the cost mentioned above disappears. More generally, in order to observe a jump bid aimed at hiding information, we need, at least, three bidders with the following characteristics. At least one bidder must have initially coarser information, which can become finer by observing the exact drop out value of one or more bidders. At least one bidder must have an incentive to prevent the acquisition of this finer information, which means that 1) either the more precise information would have a more positive (or less negative) impact on some of the opponent's value rather than on the value of the bidder who jump bids; or 2) that the

\footnotetext{
${ }^{1}$ The two market could be geographically different and thus we could think of their information to be independent, or they could not. The only requirement here is that the information is not perfectly correlated.

${ }^{2}$ Throughout the paper, we use the convention to refer to a bidder as "she".
} 
jump bids enables the bidder who jump bids to preserve an informational advantage that induces the less informed bidder to bid less aggressively. We illustrate that the latter is the case when an informational advantage over a common value component imposes a winner's curse on the less informed bidder. In other words, either asymmetry in the value structure or in the informational structure is needed.

Whenever information aggregation is considered a key issue, it is paramount to understand if and how bidders can affect it. This is particularly relevant as in practice most open auction formats allow the bidders or the auctioneer to call a price higher than the highest standing price, and bidders do make use of such possibility. While the example provided above is stylized, situations where an incentive to jump bid is present are common. For examples that are meant to be suggestive of the situations we have in mind, see section 6.

We see our paper as a first step towards a better understanding of a bidder's strategic behavior in an open auction when the action space is larger. The enlarged action space and the resulting complexity of the environment make it more difficult to draw unambiguous predictions regarding the effect of hiding information. Still, we think that we are able to point out the main motivations behind the desire to hide information and their consequences in terms of revenue and efficiency. We show that jump bids with this motivation may arise in several environments, even in symmetric ones. However, the conjunction of symmetry and of a condition on the monotonicity of value functions rules out the possibility of jump bids arising for this motive. We also show that jump bids may have several strategically complex effects and that the possibility of calling a price, even when it is not used, may dramatically affect the issue of the auction. Eventually, we prove that the effect of allowing jump bids on efficiency and revenue is ambiguous. Even though the direct effect of a jump bid on efficiency and revenue is a priori negative (a bidder calls a price in order to lower the price he pays or to win the auction in situations he would not win if the information was not hidden), the indirect effects may more than counterbalance it. 


\section{Related Literature}

A bidder may call a price higher than the highest standing bid moved by one of two rather opposite strategic motivations: providing more information to other bidders or hiding information to them. The first motivation has already been pointed out in the existing literature on jump bidding. The second one is novel to our contribution. According to the first rationale, a jump bid provides finer information to the opponents by signaling that the private information held by the bidder who jump bids is good. This strategy can be profitable to the extent that it induces the opponents to quit earlier than they would otherwise. ${ }^{3}$

There are two main types of signaling models suggested by the literature. One is based on the idea that signaling may discourage the acquisition of costly information, while the other is a pure signaling model. The first contribution suggesting the former preemptive motivation is Fishman (1988). Other related works are Hirshleifer and PNG (1989), Bhattacharyya (1992), Bernhardt and Scoones (1993), and Michelucci (2012).

Fishman (1988) presents a two-bidder independent private value model in which one of the two bidders has an informational advantage in that she is able to costly discover her valuation prior to the start of the auction, while the other bidder does not. If the first bidder's value is above some critical threshold, a jump bid that pre-empts the second bidder from investing and competing is placed. The effect of a jump bid in this setting is anti-competitive and reduces the seller's revenue. Essentially, the model introduces an entry deterrence scenario, which requires costly information acquisition to work. This model fits very nicely those applications for which discovering finer information is costly, however it cannot be applied more generally. ${ }^{4}$

The other leading justification for jump bidding has been proposed by Avery (1998). Using a symmetric model with affiliated valuations he shows that jump bidding can be

\footnotetext{
${ }^{3}$ In general, a jump bid may, at the same time, hide some information as well as signal some other.

${ }^{4}$ The assumption of private values is restrictive. For a model that looks at the incentive to jump bid when the finer information involves a common value element; see Michelucci (2012).
} 
employed to select the strongest bidder during the first stage. During this stage, strong bidders (with high types) signal that their type is high by making a jump bid. The signaling induces asymmetric bidding behavior in the second stage of the game with a strong bidder committing to a more aggressive strategy than a weak bidder. Such equilibrium behavior can be viewed, as the author points out, as a form of implicit collusion.

In any jump bid signaling model, the receiver needs to quit earlier than she would do otherwise, regardless of the fact that in an interdependent value setting a jump bid raises her expected value. In the absence of bidding costs, this latter behavior can be part of an equilibrium strategy only if the bidder who observes the jump bid can infer that she has zero probability of winning. In this case, she is as well off by quitting earlier. However, the equilibrium is typically not robust to trembles and not a perfect bayesian equilibrium; see Avery (1998).

In this paper, we focus on the hiding information rationale. With our motivation, bidders do not need to interpret the strategic meaning of a jump bid: bidders simply need to rationally process the available information as it happens in a model without jump bids. The effect of a jump bid that we stress is to foreclose access to finer information so that the information that bidders get to process is coarser. There is also some information foreclosure in Fishman (1988), but there are crucial differences. First, in his model the bidder who observes the jump bid can still acquire the finer information, even if, in equilibrium, she will not. Instead, in our model, the finer information is simply no longer available. Second, we do not need costly information acquisition to generate jump bids, and so we can explain jump bids for applications where Fishman (1988)'s preemptive motive cannot be applied.

Even though there is no explicit cost of acquiring information in our setting, in an open auction, the winner might experience ex-post regret, that is she might experience a loss when winning. The reason why a bidder might be active at a price at which she would make a loss if she were to win is that such loss is, in expected terms, more than compensated by the potential profits of winning at a higher price, later 
in the auction. In other words, the bidder is active at lower prices in the hope of aggregating favorable information later on. Thus we can view the mentioned expected losses as the implicit cost of aggregating information. This possibility does not arise in most of the the standard literature as some technical single crossing conditions are assumed to guarantee that the efficient outcome is implementable and no ex-post regret is experienced in equilibrium. ${ }^{5}$ We deal with this type of environment in section 6.2 and show that jump bids can increase revenues and efficiency in cases in which the standard English auction without jump bids fails to aggregate smoothy new information.

That bidders might be active in an open auction in order to aggregate new information is a point that has also been made by Compte and Jehiel (2004a) and Compte and Jehiel (2007). Compte and Jehiel (2004a) provides a private value model where, with some probability, bidders may receive a better estimate about their private valuation at some exogenously determined random time. If there are enough bidders in the auction, it may be profitable for some bidders to wait and see for favorable information. Such possibility raises both efficiency and revenues compared to a sealed-bid format. A similar insight is also present in Compte and Jehiel (2007): a bidder may stay active beyond her initial expected valuation to observe the strength of the competition. If competition is not intense, she can invest to get to know her exact valuation. Instead, here we point out some limits to the ability of the English auction (without jump bids) to aggregate information. Namely that if the bidders who might wait and see are not symmetric, a free rider problem might originate, and preclude the aggregation of new information altogether. In this case, allowing for jump bids can increase both revenue and efficiency.

The remaining of the paper is organized as follows. Section 3 introduces the model. Section 4 presents two natural environments where an equilibrium jump bid emerges. Section 5 considers the question of jump bids in a symmetric environment. Section 6 studies strategically more complex environments, illustrates some properties of jump

\footnotetext{
${ }^{5}$ For an analysis of the efficiency properties of the English auction when these conditions are violated and some relevant examples, see Hernando-Veciana and Michelucci (2011).
} 
bids, and shows that there is no clear-cut effect of jump bids on revenue and efficiency. Section 7 discusses and extends ideas introduced in the paper. Section 8 concludes.

\section{Auction setting}

We analyze a modified version of the Japanese Auction (JA), which aims at capturing the truly dynamic features of the English Auction (EA) that cannot be represented when adopting the standard JA format.

\subsection{Environment}

A set $N$ of $i:=1 . . n$ bidders is present at the start of the auction. No further entry takes place after the auction has started, and the decision to exit the auction is irreversible. Bidder $i$ 's private information is represented by a unidimensional signal $t_{i} \in T_{i}$, while the vector $t_{-i} \in T_{-i}$ contains the $n-1$ signal of i's opponents. The bidders' valuations are interdependent, i.e., $v_{i}\left(t_{i}, t_{-i}\right)$, with $v_{i}$ weakly increasing in $t_{j}$ for all arguments. While $t_{i}$ is private to bidder $i$, the value functions $v_{i}$ as well as the cumulative distribution functions, $F_{i}$ from which the signals $t_{i}$ are independently drawn ${ }^{6}$ are common knowledge among bidders. In some of the following analysis we assume discrete type space. We find this more convenient to illustrate our points in the cleanest way, but it should be apparent that an environment with a continuous type space can always be constructed to derive the very same insights.

\section{$3.2 \quad$ Auction Rules}

We consider two versions of the Japanese auction. First, the standard Japanese auction without jump bids we will call the $C$ game. ${ }^{7}$ Second, the $J$ game, is a Japanese Auction in which jump bids are allowed. The latter is defined as follows. The price starts from a very low value, which we normalize to zero, and it is increased at a constant pace by

\footnotetext{
${ }^{6}$ Except in some specific cases that we will mention

${ }^{7}$ The price continuously increases.
} 
an exogenous device such as a clock. Bidders are considered as active only if they are currently pressing a button. At any point in time, i.e., at any price $p \geq 0$ indicated by the clock at a specific instant of time, each Bidder $i$ faces a decision with three alternatives: exit at $p$ by releasing the button, remain active by keeping their hands on the button and, finally, call a price. The identity of the bidders who quit is publicly revealed so that a bidder knows exactly against whom she is competing at anytime during the auction. Using her third option a bidder can interrupt the exogenous price increase. The clock is then stopped at the price indicated at that time and then reset at the price that has been called. In case more than one bidder simultaneously stops the clock, the right of calling the price is assigned randomly by the auctioneer to one of the bidders who proposed the highest called price, and her identity is made common knowledge. ${ }^{8}$ We refer to the k-th jump bid placed by bidder $i$ as $J_{i}^{k}, k \in\{1 . . K\} .{ }^{9}$ A jump bid, $J_{i}^{k}$, is defined by the pair $\left(\underline{p}_{i}^{k}, \bar{p}_{i}^{k}\right)$, where $\underline{p}_{i}^{k}$ is the price at which bidder $i$ stops the clock to place her $k$-th jump bid, and $\bar{p}_{i}^{k}>\underline{p}_{i}^{k}$ is the price that is called. Let $k_{i}(p)$ be the number of jump bids placed by bidder $i$ up to price $p$. We can then represent Bidder $i$ 's decision at $p$ by $a_{i}(p) \in\left\{\right.$ exit, active, $\left.\bar{p}_{i}^{k_{i}(p)+1}\right\}$. After jump bid $J_{i}^{k}$ all the bidders that were active at price $\underline{p}_{i}^{k}$ need to independently decide whether they want to be active also at price $\bar{p}_{i}^{k}$; the identities of the bidders who do not match the jump bid are publicly revealed. The auction ends either when a price is called and no other bidder matches it or when in the continuous price increase phase the last but one bidder quits. In the first case, the winning bid is given by the price that was called, in the second, by the price at which the last but one bidder exited. We also denote by $h_{i}(p) \equiv\left(J_{i}(p), d_{i}(p)\right)$ all the information publicly available at price $p$ regarding Bidder $i$. This consists of two entries: $J_{i}(p)$, the set of jump bids placed by bidder $i$ up to price $p$; and $d_{i}(p)$, which records the value $p$ if bidder $i$ is active at the current price, $p^{\prime}$ if bidder $i$ has dropped at $p^{\prime}<p$, and finally $\left(\underline{p}_{j}^{k}, \bar{p}_{j}^{k}\right)$, if bidder $i$ did not match the $k^{t h}$ jump bid of Bidder $j \neq i$. The n-dimensional vector $H(p) \equiv\left(h_{1}(p), \ldots, h_{n}(p)\right)$ therefore

\footnotetext{
${ }^{8}$ The fact that other bidders also had stopped the clock is not revealed nor are the bidders' identity.
}

${ }^{9}$ The identity of the bidder who places the jump bid is common knowledge. 
records all publicly available history up to price $p$.

We assume the following tie-breaking rule. If the $k$ last active bidders (with $k \geq 2$ ) leave the auction at the same price, $p$, the good is sold at price $p$ with a probability $1 / k$ to each of the $k$ last active bidders.

For the sake of simplicity and in order to rule out less interesting equilibria, we add the following standard assumption.

Assumption 1. Bidders do not play weakly dominated strategies.

\section{Information Aggregation and Jump Bids}

This section presents natural set-ups where jump bids emerge in equilibrium and for which the rationale behind jump bidding is simple to understand from a strategic view point. We leave the analysis of strategically more involved scenarios to section 6 , which enables us to highlight some additional interesting features. In the introduction we argued that in order to observe jump bids in equilibrium some asymmetries are needed. In the current section, we first present a set-up where the crucial asymmetry is in the valuation structure, and then we move to a second one where the crucial asymmetry is in the information structure, which imposes a winner's curse that depresses the bid of the less informed bidder. The strategic analysis is simple in both cases because there is only one piece of information to be hidden and therefore no future opportunity to manipulate information later on.

\subsection{Asymmetric values}

Let us start by modeling in the most stylized way the situation described in the introduction with two local distributors competing with a bigger foreign distributor. As already noted this is a situation where one bidder might benefit more than others from aggregating new information during the auction. A jump bid can be used to prevent this bidder from acquiring the finer information that she would need to become more competitive. 


\section{Set-up 1.}

- For $i: 1,2, v_{i}=t_{i}, t_{i} \in\{l, m, h\}, \operatorname{Pr}\left(t_{i}=l\right)=\operatorname{Pr}\left(t_{i}=m\right)=\operatorname{Pr}\left(t_{i}=h\right)=\frac{1}{3}$.

- $v_{3}=L$, if $t_{1}=l$ and/or $t_{2}=l ; v_{3}=H$, otherwise.

- $0 \leq L<l<m<h<H$

This simple example already captures some interesting points.

We begin with the $C$ game, without jump bids. We first note that it is not immediate that the big distributor, Bidder 3, decides to stay active and learn finer information about the market by observing her opponents' bidding behavior.

Because of Assumption 1, in any equilibrium of the $C$ game, Bidders 1 and 2 leave the auction when the price reaches their values, which is their unique weakly dominant strategy. At the beginning of the auction, Bidder 3 does not know her valuation for the good and it is not immediate that she will decide to stay active and learn finer information about the market by observing her opponents' bidding behaviors (if she observes that Bidder 1 and 2 stay active when the price is strictly higher than $l$, she stays active up to $H$ ). As a matter of fact, if she does so, the big distributor may incur a loss when she wins the auction and the market is not deep enough i.e. when $t_{1}=t_{2}=l$. Her loss in that case is equal to $L-l$. Thus, she will be willing to stay active up to $l$ only if the expected gain when the market is deep enough: $4 H-3 h-m$, outweigh such losses, i.e. when $4 H+L-3 h-m-l \geq 0 .{ }^{10}$

Therefore, if assumption 1 is satisfied, and $4 H+L-3 h-m-l \geq 0$, in any equilibrium of the $C$ game, Bidder 1 and 2 leave the auction when the price reaches their respective valuations for the good, Bidder 3 stays active until the auction reaches $l$, immediately leaves if one of the two other bidders leave at that price and otherwise

\footnotetext{
${ }^{10}$ In that case, with probability $\frac{1}{9}, t_{1}=t_{2}=l$, and Bidder 3 loses $l-L$. With probability $\frac{3}{9},\left(t_{1}, t_{2}\right)$ is equal to $(h, h),(m, h)$ or $(h, m)$ and Bidder 3 earns a profit, $H-h$. With probability $\frac{1}{9}, t_{1}=t_{2}=m$ and Bidder 3 earns a profit, $H-m$. In the other cases, Bidder 3 derives a zero profit so that Bidder 3 derives the profit $\frac{4 H+L-3 h-m-l}{9}$ if she stays active up to $l$ and observes other Bidders' behaviors at that price.
} 
stays active until the auction reaches $H$. The auction is inefficient with a probability $1 / 9$ and the expected revenue is $\frac{5 l+m+3 h}{9}$.

Now, let us consider the $J$ game, assuming that the condition $4 H+L-3 h-m-l \geq 0$ is satisfied. Before presenting an equilibrium with a jump bid, we begin by showing intuitively why the type of equilibrium that we mention for the $C$ game may not be the only one in the $J$ game.

Local distributors know that the big distributor only cares about distinguishing the states of the world in which at least one of them has a type $l$ from all the other states for which she holds the highest valuation, and that she would get this information when the price reaches $l .{ }^{11}$ By placing a jump bid from any price strictly lower than $l$ to a price of $m$, a local distributor with the highest type, say Bidder 1, can prevent the exact drop out value of Bidder 2 from being disclosed (whenever this differs from $h$ ) in order not to allow Bidder 3 to distinguish whether $t_{2}$ is equal to $l$ or $m$. In this case, after observing such a jump bid, Bidder 3 since she does not know whether $t_{2}=l$ or $t_{2}=m$ would leave at a price equal to $\max \left(m, \frac{H+L}{2}\right) .{ }^{12}$ Therefore, when $t_{1}=h$, Bidder 1 , rather than staying active until $h$ without calling a price, may prefer calling price $m$ at the beginning of the auction.

To see whether this is profitable, we compare the scenario where Bidder 1 lets the price increase continuously with the one in which she calls a price $m$ at the beginning of the auction, assuming that Bidder 2 never calls a price and leaves the auction when the price is equal to her valuation for the good. In the first case, the profits of Bidder 1 when $t_{1}=h$ are $\pi_{1}^{c}=\frac{1}{3}(h-l)$, while in the latter they are equal to $\pi_{1}^{j}=$ $\max \left(0 ; \frac{2}{3}\left(h-\max \left(m, \frac{H+L}{2}\right)\right)\right)$. Thus, the jump bid is profitable whenever $h+l>H+L$ and $h+l>2 m$. We also need to check that Bidder 3 stays active until $l$ when she does

\footnotetext{
${ }^{11}$ Since Bidder 1 and 2 do not play dominated strategies and therefore do no stay active when the price is strictly higher than their valuations for the good.

${ }^{12}$ When Bidder 2 does not match the jump bid, Bidder 3 remains uncertain about the real depth of the market so that she drops out when the price reaches her expected valuation, i.e., at $E\left(\tilde{v}_{3} \mid \tilde{t}_{1}=\right.$ $\left.h, \tilde{t}_{2} \neq h\right)=\frac{H+L}{2}$. The final price may also be equal to $m$ if $\frac{H+L}{2} \leq m$.
} 
not observe a jump bid. ${ }^{13}$ Otherwise, making a jump bid would not be worthwhile. This is the case if $L-l+H-m>0$ or equivalently $H+L>m+l$. We state this observation more formally in the following proposition.

Result 1. If $h+l>H+L>m+l$ and $h+l>2 m$, there exists an equilibrium of the $J$ game in which Bidder $i$, with $i=1,2$, when her valuation for the good is equal to $h$, calls price $m$ at the beginning of the auction and then stays active until the price reaches $h$. If her valuations differs from $h$, she does not call a price and stays active as long as the price is strictly lower than her valuation for the good. In this equilibrium, Bidder 3 never calls a price. If no price is called, Bidder 3 stays active until the auction reaches $l$, immediately leaves if one of the two other bidders leaves at that price and otherwise stays active until the auction reaches $H$. If $m$ is called at the beginning of the auction, Bidder 3 stays active. If the bidder who did not call the price does not stay active, Bidder 3 leaves the auction at a price equal to $\max \left(m, \frac{H+L}{2}\right)$ otherwise she stays active until the auction reaches $H$.

Proof. We consider the following strategies.

Bidder $i$, with $i=1,2$. When $t_{i}=l$ or $t_{i}=m$, she never calls a price and stays active if and only if the current price is strictly lower than $t_{i}$. When the price is higher or equal than $t_{i}$, she leaves the auction. When $t_{i}=h$, she calls a price $m$ at the beginning of the auction and stays active without calling a price as long as the price is strictly lower than $h$.

Bidder 3 .

She never calls a price.

When no price is called, she stays active until the auction reaches $l$, immediately leaves if one of the two other bidders leave at that price and otherwise stay active until the auction reaches $H$.

\footnotetext{
${ }^{13}$ As a matter of fact, since Bidder $i$, with $i=1,2$, calls a price when $t_{i}=h$, the fact that no price is called raises the likelihood of the negative event $\left(t_{1}, t_{2}\right)=(l, l)$. Therefore, we need to check that bidder does not prefer leaving the auction before it reaches $l$.
} 
If Bidders 1 and 2 are active and one of them calls a price $\left(p_{1}, p_{2}\right)$. If $p_{2} \geq h$, Bidder 3 immediately leaves the auction. If $p_{1}>l$ or $p_{2}<l$, Bidder 3 follows the same strategy as when no price is called. If $p_{1} \leq l \leq p_{2}<m$, bidder 3 stays active after the jump bid ; if both other bidders stay active after the jump bid, Bidder 3 stays active up to price $H$; otherwise she immediately leaves the auction. If $p_{1} \leq l$ and $m \leq p_{2}<h$, Bidder 3 stays active after the jump bid ; if both other bidders stay active after the jump bid, Bidder 3 stays active up to price $H$ otherwise she leaves the auction at a price equal to $\max \left(m, \frac{H+L}{2}\right)$.

One can easily check, that these strategies are constitutive of an equilibrium and that, in this equilibrium, bidders behave as described in Result 1.

In this equilibrium of the $J$ game, the allocation is not efficient with a probability $\frac{2}{9}$, when $\left(t_{1}, t_{2}\right) \in\{(m, h),(h, m)\}$. When $m \geq \frac{H+L}{2}$, the expected revenue is $\frac{3 l+5 m+h}{9}$ while, in the $\mathrm{C}$ game, it is equal to $\frac{5 l+m+3 h}{9}\left(>\frac{3 l+5 m+h}{9}\right.$ when $\left.h+l>2 m\right)$. When $m<\frac{H+L}{2}$, the expected revenue is $\frac{2 H+2 L+3 m+h+l}{9}$ while, in the $\mathrm{C}$ game, it is equal to $\frac{5 l+m+3 h}{9}\left(>\frac{2 H+2 L+3 m+h+l}{9}\right.$ when $\left.h+l>H+L\right)$. Hence, efficiency and revenue are strictly lower with this equilibrium of the $J$ game than with any equilibrium of the $C$ game.

\subsection{Asymmetric Information: Jump Bids and the Winner's Curse}

In this subsection, we show that the fear of suffering from the winner's curse can be exploited by another bidder through the use of a jump bid. The crucial point here is that there is asymmetric information regarding a common value element of the bidders' valuations for the object, and a jump bid may create a winner's curse issue in an environment where it would not exist without it. We also show that the level of the jump bid may partially reveal the value of the signal that the jump bid intends to hide. 
Let us consider the following 3 bidders' framework. Bidders' valuations depend on the value of $s ; s$ is privately observed by Bidders 1 and 2 , that is $t_{1}=t_{2}=s$. Bidder 3 does not know the realization of $s$, she only knows its distribution function, $F$. $F(0)=0, F(1)=1$ and $F$ is continuous and strictly increasing on the interval $[0,1]$. We also assume that bidders 2 and 3 have extra motivations for buying the good so that valuations can be defined as follows. ${ }^{14}$

\section{Set-up 2.}

- $v_{1}=s$

- $v_{2}=s+\frac{1}{n}+\varepsilon$ with $\varepsilon>0$ and arbitrarily small

- $v_{3}=s+\frac{1}{n}$

We first consider the case when $n=1 . .^{15}$

In the unique equilibrium with undominated strategies of the $\mathrm{C}$ game, Bidder 1 leaves the auction at a price equal to $s$, then Bidder 3 leaves the auction at a price equal to $q+1, q$ being the price at which Bidder 1 leaves the auction if it is in the interval $[0,1]$ and 1 otherwise and Bidder 2 obtains the good at a price equal to $1+s .{ }^{16}$

Result 2. There exists an equilibrium of the $J$ game in which, whatever the value of $s$ is Bidder 2 makes a jump bid to the price of 1 at the very start of the auction and Bidders 1 and 3 immediately leave the auction.

\footnotetext{
${ }^{14}$ The considered framework is close to the standard common value auction framework. Such a situation may arise, for example in the following situation. The good for sale is the exploration and exploitation rights (oil) of a maritime area. Both Bidders 1 and 2 have an access to a geological study on the wealth of this area $(s)$. Bidders 2 and 3 already have a well established branch in the considered country $(+1)$. Bidder 2 owns the exploration and exploitation rights of the closest exploitable maritime area $(+\varepsilon)$.

${ }^{15} \mathrm{n}$ is assumed to belong to the set of natural numbers.

${ }^{16}$ One may wonder why Bidder 1 participates in the auction even though she loses with probability 1. We may design an example in which Bidder 1 wins with a strictly positive probability and still we would observe the same type of phenomena. We prefer considering this framework for the sake of simplicity.
} 
Intuition of the proof of the equilibrium. It is straightforward that Bidder 1 cannot raise her profit by staying active when the price is equal to 1 . Now, let us consider Bidder 3. Since Bidder 2 always makes a jump bid to 1, Bidder 3 cannot revise her belief about the value of $s$ after observing the jump bid. If Bidder 3 stays active, she only obtains the good if Bidder 2 leaves the auction before her. Suppose that Bidder 2 leaves the auction when the price is equal to $s+1+\varepsilon$ (which is a dominant strategy). Then, if Bidder 3 wins the auction, she pays a price equal to $s+1+\varepsilon$, strictly higher than Bidder 3's valuation. Since winning the good will always be associated with a loss and $v_{3}$ is at least equal to 1 , Bidder 3 prefers leaving the auction immediately when the jump bid is equal to 1 . On Bidder 2's side, making a jump bid up to 1 is not costly since Bidder 3 will never leave the auction for a price below 1. Besides, by calling the price he obtains the good precisely at that price.

In this example, the allocation in the equilibrium of the $\mathrm{J}$ game that we consider is the same as the allocation in the unique equilibrium with undominated strategies of the $\mathrm{C}$ game. In both cases, Bidder 2 always obtains the good. However, the jump bid may dramatically reduce the price. On average, the price reduction is equal to $E(s)$. The motivation for the jump bid builds on the winner's curse that Bidder 3 may incur in case she wins the object. Since Bidder 3's valuation is always lower than Bidder 2's, bidder 3 knows that winning the auction against Bidder 2 cannot be profitable. Besides, because of the jump bid, Bidder 3 cannot discover the value of $s$ without winning the auction at a price strictly higher than her valuation for the good. Therefore, she prefers leaving the auction. On Bidder 2's side, it is not costly to make a jump bid up to 1 since for any value of $s$, Bidder 3 never leaves the auction when the price is lower than 1 . The possibility for Bidder 2 to make a jump bid allows her to fully exploit her small advantage over Bidder 3 .

Now, let us turn to the $n \geq 2$ case.

As compared to the $n=1$ case, the unique equilibrium with undominated strategies of the $\mathrm{C}$ game remains unchanged. Now, there exists an equilibrium of the $\mathrm{J}$ game in which Bidder 2 makes a jump bid at a price equal to $k / n$ with $k$ being a strictly positive 
integer such that $s \in\left(\frac{k-1}{n}, \frac{k}{n}\right]$. Bidder 1 leaves the auction immediately after the jump bid and Bidder 3 leaves after having observed that Bidder 1 has left.

Intuition of the proof of the equilibrium. The main difference with the $n=1$ case is that, now, Bidder 3 can revise her expected value conditional on observing the jump bid chosen by Bidder 2. As a matter of fact, if the jump bid is equal to $\frac{k}{n}$, Bidder 3 learns that $s$ lies in the interval $\left(\frac{k-1}{n}, \frac{k}{n}\right]$, therefore $v_{3}$ lies in the interval $\left(\frac{k}{n}, \frac{k+1}{n}\right]$. But again, if Bidder 3 wins the auction, she knows that she is a victim of the winner's curse (considering that Bidder 2 leaves the auction when the price is equal to $s+\frac{1}{n}+\varepsilon$ ). Therefore, Bidder 3 prefers leaving the auction at a price equal to $\frac{k}{n}$.

On Bidder 2's side, it is no longer profitable to make a jump bid equal to 1 whatever the value of $s$. As a matter of fact, when $s<\frac{n-1}{n}$, Bidder 2 may obtain the good for a price strictly lower than 1 without submitting a jump bid (since $v_{1}, v_{3}<1$ ). However, it may still be profitable for Bidder 2 to hide the exact value of $s$ by submitting jump bids. In order to do so, Bidder 2 makes different jump bids depending on the value of $s$. With this jump bid, Bidder 2 prevents the precise value of $s$ from being revealed through the auction process but she also reveals in which interval $\left(\frac{k-1}{n}, \frac{k}{n}\right], s$ lies. The jump bid makes the information revelation coarser. The length of the interval is equal to the advantage of Bidders 2 and 3 over Bidder 1.

\section{$5 \quad$ Symmetric Settings}

In the previous section, we introduced two frameworks in which equilibrium jump bids may arise. Both frameworks are not symmetric. This is not a coincidence. In this section we show that in a standard symmetric setting we should not expect to observe any jump bid that is motivated exclusively by a hiding information motivation. To show the point let us first state the following restriction we impose on the equilibrium strategies we allow.

Assumption 2. We exclude equilibrium strategies that prescribe to any Bidder $i$ not to match a jump bid $J_{j}^{k}=\left(\underline{p}_{j}^{k}, \bar{p}_{j}^{k}\right)$ by Bidder $j$, if $\bar{p}_{j}^{k}<E\left(v_{i} \mid t_{i}, t_{j}=t_{i}, H\left(\underline{p}_{j}^{k}\right), d_{r}\left(\bar{p}_{j}^{k}\right)=\left(\underline{p}_{j}^{k}, \bar{p}_{j}^{k}\right), \forall r: d_{r}(\right.$ 
The rational for such restriction on the "matching jump bids policy" is that we want to isolate the signaling motivation from our novel explanation based on hiding information. Essentially the restriction says that following a jump bid all bidders that are active at the moment the jump bid is placed will match the jump bid whenever its value it is less or equal than their expected valuation conditional on the most pessimistic equilibrium information that could be learned after the jump bid is placed (that is all other active bidders do not match the jump bid), and the equilibrium information gathered prior the jump bid. It also conditions on the type of the bidder who placed the jump bid to be equal to the type of the bidder who is evaluating whether to match the jump, because we further assume that in the continuos price increase phase of the J game bidders use symmetric strategies. ${ }^{17}$

Without Assumption 2 it is easy to see that we can find a symmetric equilibrium even in a standard symmetric setting: bidders can jump bid to the bid prescribed by FPA equilibrium strategy and the highest bid is never matched. ${ }^{18}$ But such jump bids are based on a signaling motivation as they require bidders not to match a jump bid even when their expected value for the object is strictly higher than the jump bid. Thus, the Proposition below shows that in a symmetric setting whenever we rule out jump bids that have purely a signaling motivation, we cannot have jump bids aimed at hiding information either. This is not true in the asymmetric settings studied earlier as all the equilibria we presented there satisfy assumption 2.

\footnotetext{
${ }^{17}$ Notice that allowing for jump bids does not exclude the standard asymmetric equilibria that are well known to arise in the English Auction such as one bidder committing to stay active till a very high value regardless of his type and all the others quitting at a very low value regardless of their type. Thus, we still have multiplicity of equilibria even if jump bids are allowed. We take as a benchmark the symmetric equilibrium of the $\mathrm{C}$ game, and we further assume that bidders use symmetric strategies in the continuos price increase phases of the $\mathrm{J}$ game in order to evaluate whether jump bids can arise for a hiding information motivation rather than from inducing asymmetric behavior in a symmetric setting.

${ }^{18}$ To ensure that such an equilibrium jump bid can be part of an equilibrium, it is possible to design appropriately the out of equilibrium behavior that follows if any bidder matches the highest jump bid so that all bidders still active follow a symmetric strictly increasing strategy
} 
Proposition 1. Suppose that $v_{i}\left(t_{i}, t_{-i}\right)$ is strictly increasing in $t_{i}$ for any profile of the opponents' signals, $t_{-i}$, and weakly increasing in $t_{j}$ for any $j$ with all types $t_{i}$ drawn independently, and that Assumption 2 applies. Then, no jump bid can arise in the equilibrium of the symmetric value model.

Proof. See Appendix.

What the proposition above essentially does is to look at the effect caused to the symmetric equilibrium of the $\mathrm{C}$ game once we allow for jump bids. Given our restrictions, a jump bid can be profitable only if it succeeded in depressing the expected second highest bid. The reason why this is not possible is because Assumption 2 forces the bidder to use all equilibrium information, and by the Law of Iterated Expectations we can conclude that the expected price paid by the winner whenever the auction ends with a continuos price phase is the same regardless of the jump bids that have occurred. Conversely, if the auction ends because the jump bid is not matched this implies the price paid is higher than the expected price that would have been paid if jump bids were not placed. Thus, jump bids are not profitable under our assumption in a symmetric setting.

However, let us point out that the environment of section 4.1 can be made exante symmetric, and jump bids there can arise. The simple modification needed is to assume that each firm now knows whether it has some informational advantage over a particular market but it does not know the identity of its opponents, that is, whether they are big but uninformed distributors or local distributors informed about their own market. The value functions below describe a plausible economic situation. However, they are not standard as we cannot rank bidders types in a way that bidders' values are strictly increasing in their own type, fixed the opponents type profile. Thus, the example below does not fall within the set up of Proposition 1.

\section{Set-up 3.}

- 3 bidders 
- $t_{i} \in\{l, m, T, h\}$

- $\operatorname{Pr}\left(t_{1} ; t_{2} ; t_{3}\right)=0$ if $t_{1} \neq T, t_{2} \neq T$ and $t_{3} \neq T$ or $t_{1}=t_{2}=T, t_{1}=t_{3}=T$ or $t_{2}=t_{3}=T$ and $\operatorname{Pr}\left(t_{1} ; t_{2} ; t_{3}\right)=\frac{1}{27}$ otherwise

- $v_{i}\left(t_{i}\right)=t_{i}$, if $t_{i} \neq T$

- $v_{i}(T)=L$, if $t_{j}=l$, for some $j \neq i ; v_{i}(T)=H$, if $t_{j} \neq l, \forall j \neq i$

- $0 \leq L<l<m<h<H$

In the above setting, types $t_{i} \neq T$ can be seen as informed types so that if a bidder draws one of these types, her valuation is independent of the other bidders' information. Conversely, if a bidder draws a type $T$, her value is low $(L)$ if at least one other bidder has drawn a low type $(l)$, and it is high $(H)$ if all bidders have drawn a good enough type $(\neq l)$. It is easy to show that if $h+l>H+L>m+l$ and $h+l>2 m$ hold, it is profitable for a bidder with type $h$ to place a jump bid from a value lower than $l$ to $m$ for the same reason as before.

\section{Strategically More Complex Environments}

In the previous sections, we introduced simple examples in order to show how equilibrium jump bids may emerge. In this section, we consider strategically more complex environments in order to illustrate properties of jump bids. The extra complexity comes from analyzing a truly dynamic game where at any given price bidders decide whether to stay active, quit, or place a jump bid taking into account that other bidders can also later on manipulate the flow of information with a jump bid. We have selected specific set ups to simply illustrate the most interesting effects that this extra complexity brings.

In the first subsection we show that a bidder may be induced to jump bid by the anticipation of someone else hiding some information later on. The interesting effect that is brought about by this strategic element is that everybody is strictly worse off 
in the $\mathrm{J}$ game. This is interesting because it is generally thought that jump bids are anti-competitive and thus should be banned by the seller, but that bidders who place them are strictly better off when jump bids are allowed. Here, instead, the bidder who jump bids is better off than letting the price increase continuously, but worse off compared to the $\mathrm{C}$ game. ${ }^{19}$

In the second subsection we show that a bidder may be induced to quit earlier than she would otherwise if jump bids were not allowed. Interestingly, even though no jump bids are observed in equilibrium, the equilibrium outcome is drastically affected by the fact that bidders do have such an option.

Finally, the third subsection illustrates that there are instances in which the $\mathrm{C}$ game fails to aggregate new information, while, surprisingly, allowing for jump bids raises both revenue and efficiency.

\subsection{A Jump Bid to Prevent Another Jump Bid}

We consider a setting in which a bidder is induced to jump bid by the anticipation that another bidder may strategically hide some relevant information (via a jump bid) later on in the auction. An interesting feature illustrated by this subsection is that it may be the case that all the bidders are worse off with the equilibrium of the $J$ game than with the equilibrium of the $C$ game.

We consider the following setting:

\section{Set-up 4.}

- $t_{1} \in\{l, h\}, t_{3} \in\{L, H\}, p\left(t_{1}=l\right)=p\left(t_{3}=L\right)=1 / 2$, with $t_{1}$ and $t_{3}$ privately observed only by Bidder 1 and 3, respectively; the two distributions are independent.

- $v_{1}\left(t_{1}=l\right)=0 ; v_{1}\left(t_{1}=h\right)=3$

\footnotetext{
${ }^{19}$ Proposition 4 below illustrates a stronger result that even if one bidder was the only one allowed the option to jump bid, it is possible that she would be willing to pay to avoid having such an option.
} 
- $v_{2}\left(t_{1}=l\right)=0 ; v_{2}\left(t_{1}=h\right)=6$

- $v_{3}\left(t_{3}=L\right)=2 ; v_{3}\left(t_{3}=H\right)=3$

- $v_{4}\left(t_{3}=L\right)=0 ; v_{4}\left(t_{3}=H\right)=8$

Let us start with the analysis of the $\mathrm{C}$ game. The equilibrium strategies are as follows. Bidders 1 and Bidder 3 know the state of the world that is relevant for them and therefore stay active till their value is reached. Bidder 2 drops out as soon as Bidder 1 drops out if this happens at $p=0$ and stays active to 6, otherwise. Similarly, Bidder 4 drops as soon as Bidder 3 drops if this happens at $p=2$ and stays active till the price reaches 8 , otherwise. In this equilibrium, Bidders 2 and Bidder 4 acquire more precise information regarding the state of the world from Bidders 1 and 3 respectively. The expected revenue in the $\mathrm{C}$ game is $\frac{7}{2}$, while the expected value of the winner is $\frac{11}{2}$.

Consider the effect of allowing jump bids in this setting. The key element is that Bidder 2 can acquire the finer information that she needs regarding the state of the world at an earlier stage than Bidder 4 can. In the event Bidder 2 acquires favorable information, she is better off preventing Bidder 4 access to finer information. Conditional on having acquired good information, her expected profits are $\frac{3}{2}$ (she gets $6-3=3$ with probability $\frac{1}{2}$ ) if she allows Bidder 4 to obtain more information by observing Bidder 3's drop out value. However, the profits are equal to 2 if Bidder 2 prevents access to such information by placing a jump bid from a price lower than 2 to 3 . In this latter case, Bidder 4 bids her expected value conditional on the jump bid, which equals to 4 , and Bidder 2 always makes a profit equal to $6-4=2>\frac{3}{2}$. Bidder 4 anticipates Bidder 2's jump bid. If she lets Bidder 2 aggregate the finer information, her expected profits are equal to $\frac{3}{4}$ (when $t_{1}=l$, she loses 2 when $t_{3}=L$ and wins 5 when $\left.t_{3}=H\right)$. However, Bidder 4 can do better by placing a jump bid from the price zero to 3. In this case, she wins for sure at that price as Bidder 2's expected value conditional on the jump is also 3. This yields Bidder 4 an expected profit of $1>\frac{3}{4}$, thus the jump bid is profitable.

In the equilibrium of the $J$ game, Bidder 4 always wins. This yields a revenue of 
$3<\frac{7}{2}$, and the expected value of the winner is $4<\frac{11}{2}$. It is easy to see that all bidders are also worse off since in the $\mathrm{J}$ game the only bidder that can win is Bidder 4 and her expected profit is equal to 1 compared to $\frac{5}{4}$ in the $\mathrm{C}$ game.

We report the main result of this subsection in the proposition below.

Proposition 2. The equilibrium of the J game can be Pareto dominated by the equilibrium of the $C$ game.

Proof. See above.

\subsection{The Hidden Impact of Allowing Jump Bids}

In this subsection and the following one, we focus on an environment where in the C game some bidders might experience ex-post regret in equilibrium (see HernandoVeciana and Michelucci (2011)).

In this subsection, if jump bids are not allowed, the private information that bidders hold is aggregated in a very desirable way thanks to the possibility of the wait and see strategy described in the introduction. Allowing bidders to call a price causes both efficiency and revenue to drop. Conversely, the following subsection provides a new insight: the information fails to aggregate precisely because of the cost of staying active when other competitors are also active may lead to a free rider-problem. This results in no bidder willing to acquire finer information by staying active in the auction. The possibility of jump bidding here allows the bidder with the ex-ante higher valuation to hide the piece of information causing such free-rider problems. She may then profitably win the auction. This boosts both efficiency and revenue.

We start with the scenario where the aggregation of information is very smooth. This setting also illustrates that the anticipation of a future jump bid may induce a bidder to quit earlier than she would in the $\mathrm{C}$ game and that, even though no jump is observed in equilibrium, the equilibrium outcome in the J game substantially differs from the one in the $\mathrm{C}$ game. 


\section{Set-up 5.}

- $t_{1} \in\{5,6,7\}$ with $P\left(t_{1}=5\right)=P\left(t_{1}=6\right)=P\left(t_{1}=7\right)=\frac{1}{3}$.

- $v_{1}\left(t_{1}\right)=t_{1}$.

- $v_{2}\left(t_{1}=5\right)=0, v_{2}\left(t_{1}=6\right)=v_{2}\left(t_{1}=7\right)=9$.

- $v_{3}\left(t_{1}=5\right)=v_{3}\left(t_{1}=6\right)=0, v_{3}\left(t_{1}=7\right)=12$.

We assume that one of the bidders, Bidder 1, knows everything. Note that for both the uninformed bidders, Bidders 2 and Bidder 3, winning if $t_{1}=5$ entails a big loss as they learn that such is the state only at price $p=5$ when both value the object at a price zero.

If jump bids are prohibited, the Japanese auction allows the information to be aggregated in a very desirable way. The bidders' strategies are as follows. Bidder 1 stays active until her private value is reached. Bidder 2 quits as soon as Bidder 1 quits if that happens at a price lower than 5, and stays active until the price reaches 9 , otherwise. Bidder 3 quits as soon as Bidder 1 quits if that happens at a price lower than 6 , and stays active until the price reaches 11 , otherwise. The open format allows Bidders 2 and 3 to share the risk of winning when $t_{1}=5$, (the expected loss being $\left(\frac{1}{3}\right)\left(\frac{1}{2}\right) 5=\frac{5}{6}$ for each). Furthermore, the two bidders can split the benefits of being active at higher prices in a way that allows both to recover the expected losses. In the case $t_{1}=6$, Bidder 2 gets a profit of $9-6=3$; while if $t_{1}=7$, Bidder 3 gets a profit of $12-9=3$. The expected revenue is equal to $R^{C}=\left(\frac{1}{3}\right) 5+\left(\frac{1}{3}\right) 6+\left(\frac{1}{3}\right) 9=\frac{20}{3}$. The expected value of the winner is equal to $E^{C}=\left(\frac{1}{3}\right) 9+\left(\frac{1}{3}\right) 12=\frac{21}{3}=7$.

What happens if we allow jump bids? The smooth sharing of costs and benefits becomes unattainable and given that Bidders 2 and Bidder 3 can be active at low prices only if they do so jointly, they both quit early.

We obtain the following equilibrium path. Bidder 1 stays active until the price reaches her private value; Bidders 2 and 3 leave the auction at a price lower than 5 . To understand why this is part of an equilibrium, note that as soon as the price rises 
just above 5 , Bidder 2 learns that $t_{1} \neq 5$ and thus that $v_{2}=9$. Conversely, at that price Bidder 3 is still uncertain regarding her exact value. Bidder 2 can hide such information from Bidder 3 by calling a price equal to 7 when the current price is still in $(5,6)$. The jump bid pulls together the two cases, $t_{1}=6$ and $t_{1}=7$, for Bidder 3 , who consequently bids up to $E\left(v_{3} \mid t_{1} \neq 5\right)=6$. With the jump bid, Bidder 2 makes a sure profit of 2 as opposed to winning only if $t_{1}=6$ if she lets the price increase continuously. The latter strategy yields $\frac{1}{2}(9-6)=\frac{3}{2}<2$; therefore, Bidder 2 cannot commit not to call such a price.

But then Bidder 3 anticipating Bidder's 2 jump bid will pre-empt her from winning in the only event in which it is profitable, she is no longer willing to stay active over the price $p=5$. Since Bidder's 3 presence is necessary for Bidder 2 (her expected gain with the jump bid strategy is $\frac{4}{3}$ but her expected loss if she does not share the risk is $\frac{5}{3}$ ), the equilibrium outcome is that they both quit the auction immediately. This brings a revenue lower than 5 for any value of $t_{1}$, and it inefficiently always allocates the object to Bidder 1.

Without being aware of the implications of allowing bidders to call a price, the seller may be wrongly induced to believe that the bidders' valuations were low.

We report the main results of this subsection in the two propositions below.

Proposition 3. There may exist an equilibrium of the $J$ game whose allocation and revenue differ from the allocation and the revenue of any equilibrium of the $C$ game even though in this equilibrium of the $J$ game no price is ever called.

Proposition 4. A bidder may be willing to pay to not be allowed to call a price even in the event that she is the only bidder granted such an option.

Proof. Take the setting above where Bidder 2 is the only bidder allowed to jump bid. Since in the $\mathrm{J}$ game she never wins, she would be willing to pay up to the expected profits she makes in the $\mathrm{C}$ game to restrict her strategies space to the choice of quitting or staying active alone. 


\subsection{The Free-Rider Problem and the Existence of Efficiency and Revenue Enhancing Jump Bids}

In this setting, we show that in the $\mathrm{C}$ game perverse incentives may impede the aggregation of information and that the enlarged strategy set of the $\mathrm{J}$ game may alleviate such a problem and bring higher revenue and efficiency. The framework is as follows.

\section{Set-up 6.}

- $t_{1} \in\{9,10\}, \operatorname{Pr}\left(t_{1}=9\right)=\operatorname{Pr}\left(t_{1}=10\right)=\frac{1}{2}$.

- $v_{1}=t_{1}$.

- $v_{2}\left(t_{1}=9\right)=8, v_{2}\left(t_{1}=10\right)=13$.

- $v_{3}\left(t_{1}=9\right)=0, v_{3}\left(t_{1}=10\right)=18$.

It is similar to the previous one in so far as both Bidder 2 and Bidder 3 may have an incentive to wait and see. Differently from the previous setting, one of the them, Bidder 2, has an ex-ante value strictly higher than Bidder 1. This means that if Bidder 2 were the only bidder competing with Bidder 1, she would profitably be active over the price of 9 to be able to discover the value of $t_{1}$. Bidder 3 could potentially benefit from the active presence of Bidder 2 over the price of 9. However, if both bidders are active at that price they share the expected losses but not the expected gains. In fact, if Bidder 3 infers that $t_{1}=10$, she always wins against Bidder 2. But then Bidder 2 prefers staying active only until the price of 8 to avoid incurring a loss. In turn, if that is the case, Bidder 3 also must quit before the price reaches 9 as her expected value is lower than Bidder 1's. Hence, no aggregation of information is possible.

The equilibrium strategies of the $C$ game are as follows: Bidder 1 quits at her privately known value; Bidder 2 quits when the price reaches 8; Bidder 3 quits as soon as Bidder 2 quits if that happens at a price lower than 9. The auction performs very poorly as Bidder 1 always wins at a price of 8 , which implies that both revenue and efficiency would be higher if Bidder 3 were excluded from the competition. We can say 
that in this framework, Bidder 3 is a free rider whose presence is detrimental both for revenue and efficiency.

Now, let us look at the J game. Bidder 2 can affect Bidder's 3 bidding behavior by hiding relevant information, causing the free-rider problem. This is accomplished by stopping the clock at any price lower than 9 and calling a price of 10 . This jump bid is not matched by Bidders 1 and 3, and thus Bidder 2 wins with certainty at this price, which yields her an expected profit of $\frac{1}{2}$. That is better than in the $\mathrm{C}$ game where she never wins. Expected revenue goes up from $R^{C}=8$ in the $\mathrm{C}$ game to $R^{J}=10$ in the $\mathrm{J}$ game. Similarly, the expected value of the winner increases from $E^{C}=\frac{19}{2}$ in the $\mathrm{C}$ game to $E^{J}=\frac{21}{2}$ in the $\mathrm{J}$ game.

\subsection{The Ambiguous Effect of Jump Bids on Efficiency and Revenue}

The different environments that we introduced allow us to conclude the section with the following result.

Proposition 5. Allowing bidders to call a price can decrease or increase revenue and efficiency depending on the considered setting.

Proof. We only need to provide examples where all those possibilities are covered. The setting in sections 4.2 and 6.1 prove that revenue and efficiency can drop. The setting above proves that they can increase.

A bidder makes a jump bid to reduce information revelation either in order to obtain the good for sale in cases where she would not obtain it without the jump bid or in order to reduce the price she pays for the good. In standard cases, this leads to a drop in efficiency and revenue. However, we showed that in more complex settings, the effect of a jump bid may go in the other direction. This also means that there is no clear-cut general effect of jump bids on revenue and efficiency so that we cannot make a general recommendation regarding jump bids. 


\section{Discussion and Extensions}

In the previous sections, we showed that when a bidder's valuation depends on signals privately observed by other agents, another bidder may call a price in order to prevent the information from being revealed during the auction process. In this section, we intend to discuss to which extent the general idea of preventing information from being revealed during the auction process can be extended to other contexts.

\subsection{Bidders focusing on specific statistics}

First, we assumed that the valuations of (partially) uninformed bidders precisely depend on the signals observed by informed bidders. We do not need the interdependence to be that precise. The interdependency is the unique required element. As a matter of fact, an uninformed bidder may care about the median valuation of informed bidders or the number of informed bidders with a valuation higher than a specific threshold. This type of information may also be hidden.

Consider the following example. Mister A is moving to Newtown. Mister A does not know Newtown but he wants to quickly buy an accommodation for his family in this location. He knows his preferences and has some information about the local real estate market but not much. Mister A is in a hurry and therefore has a higher valuation for any house than almost any local buyer. Because of his ignorance, Mister A uses a rule of thumb and does not make an offer if he does not observe that at least 3 local buyers are also making offers. In that case, a local buyer may directly call a price for a specific house in order to prevent too many other local buyers from making offers. That way, Mister A also stays out of the auction. This interpretation relies on some bounded rationality on Mister A's side. He does not distinguish that his rule of thumb is not very appropriate when jump bids are possible. However, this bounded rationality seems quite credible here.

Another related scenario that fits our setting well is the one of fashion or status goods. We illustrate it with the following admittedly limiting case whose features we 
believe hold much more generally. Suppose a rich person is interested in buying a certain status quo object like a painting or a historical car in an auction. The price he pays is not the only key element. He gives a higher value to an object if several experts participating in the auction show a strong interest in it. The "status" of the object is as important as the object itself. It is easy to see that, in this case also, one of these experts can place a high bid in the beginning to prevent the rich person to potentially aggregate the information that would make her the strongest contender for the auction.

\subsection{Reserve price}

Another actor of the auction who could benefit from a process close to a jump bid is the seller. As a matter of fact, in some specific instances, a reserve price may also be used as a tool to hide information that would have been revealed otherwise during the auction process. Since we have shown that jump bids may raise the expected revenue, it seems logical that an adequate reserve price may also raise revenue, even in cases when the reserve price is always matched by at least two bidders. The following example illustrates this point.

- $t_{1}, t_{3} \in\{0,1 / 2\}, \operatorname{Pr}\left(t_{1}=0\right)=\operatorname{Pr}\left(t_{3}=0\right)=\frac{1}{2}$ and the two events are independent.

- $v_{1}=t_{1}$.

- $v_{2}\left(t_{1}=0\right)=\varepsilon, v_{2}\left(t_{1}=1 / 2\right)=3-\varepsilon$ with $\varepsilon$ arbitrarily small.

- $v_{3}=t_{3}$.

- $v_{4}\left(t_{3}=0\right)=\varepsilon, v_{4}\left(t_{3}=1 / 2\right)=3-\varepsilon$.

Without a reserve price and jump bids, in the unique equilibrium with non dominated strategies, Bidders 2 and 4 learn their valuations during the auction process. 
The allocation is efficient and the expected revenue is equal to $\frac{1}{2} \frac{1}{2}+\frac{\varepsilon}{4}+\frac{3-\varepsilon}{4}=1$. Now, the seller can choose a reserve price in the interval $\left(\frac{1}{2}, \frac{3}{2}-\varepsilon\right)$. With such a reserve price, Bidders 1 and 3 do not take part in the auction. Bidders 2 and 4 stay active until the

price reaches $\frac{3}{2}$, their expected valuation for the good. Eventually, the seller's revenue is equal to $\frac{3}{2}$.

Beyond this basic example, we observe that a reserve price may be used as a device to hide information in order to raise revenue. If bidders can manipulate information revelation during the auction process, why could not the seller also do so?

\subsection{Sniping strategies}

In a different perspective, jump bids may also be related to sniping strategies on eBaylike auctions (see Ockenfels and Roth (2002), Ockenfels and Roth (2006) or Bajari and Hortascu (2003)). In both cases, a bidder may manage to hide information. The key difference is that when a bidder makes a jump bid, she may hide information that another bidder would have revealed through her bidding behavior while a sniping bidder hides information about her own valuation of the good. More precisely, she prevents other bidders from reacting to this information because they do not have time to react to the last moment bid submitted by the sniping bidder. However, in both cases, bidders manage to hide information using specific bidding strategies.

\subsection{Costly acquisition of information}

Our work is also related to Compte and Jehiel (2004b) and Compte and Jehiel (2007). In these papers, they consider bidders who have the possibility, incurring a cost, to obtain more precise information about their valuations for the good during the auction process. Rather than paying this cost at the beginning of the auction, they may wait and see. That is to say, they observe other bidders' valuations before deciding to pay the price for discovering their valuations. A jump bid may also be used to deter such 
bidders from following this wait and see strategy. As a matter of fact, if it takes time to observe a valuation, a strong informed bidder may call a price in order to accelerate the auction process to prevent partially informed bidders from having the required time to discover their valuations.

\section{Conclusions}

We have analyzed a version of the Japanese auctions that allows bidders to stop the continuous price increase and call a price at any point during the auction. We have looked at how the possibility of calling a price affects the way information is aggregated and shown that bidders may have an incentive to alter the aggregation of information by placing jump bids to hide the drop-out value of some of their opponents. This is a novel explanation to jump bidding that contrasts with the traditional one based on signaling, for which more rather than less information is available after a price jump. The general wisdom that comes with the traditional approach is that jump bids are anticompetitive. We show instead that the strategic environment is so rich that this is not always the case. Our analysis brings powerful implications as it shows that the possibility of placing jump bids severely affects (though in general ambiguously) both revenue and efficiency. Thus, when evaluating the advantages and disadvantages of open versus sealed bid formats, great care needs to be placed on whether the setting could be favorable to jump bids. 


\section{Appendix}

\subsection{Proof of Proposition 1}

We proceed by contradiction assuming that one or multiple jump bids can be sustained at some equilibrium. Recall that we assume that bidders follow symmetric equilibrium strategies in any continuos price increase phase. This implies that: 1) if the auction ends while the price is increasing continuously, then expected profits for the bidder who jump bids would have been at least as high without the jump bid. Also, because of Assumption2, we have that: 2) the expected profits if the auction ends with a jump bid are strictly lower than if the jump bid would not have been placed. Thus, the impossibility of constructing a profitable jump bid.

1) Because of bidders use symmetric strictly increasing strategy in the continuos price phase of the $\mathrm{J}$ game, and because we assume in 1) that the game ends during this phase, the winner is the bidder with the highest type whether or not jump bids are placed, and the price paid is determined by the exit price of the second highest type (whether or not jump bids are placed). Moreover, either the jump bid does not reveal the type of the bidder who jump bids or it does. In the former case, the equilibrium strategy for the remaining active bidders differ from the one in the standard $\mathrm{C}$ game only in so far as for some of the bidders who have dropped out (the ones that have not matched the jump(s) bid), they need to condition on the coarser information that their type is within some range that can be inferred from not having matched the jump bid. But then, by the Law of Iterated Expectations, the expected price at which the second highest type drops is then the same both with jumps bids or without. In the latter case, the equilibrium strategy of the second highest bidder can condition also on the inferred type of the highest bidder the expected price is strictly higher with the jump $\operatorname{bid}(\mathrm{s})$.

2) Suppose now that the auction ends with a jump bid, that is no bidder matches it. Assumption 2 provides a lower bound on the value of the jump bid. We just need to show that such lower bound is strictly bigger than the expected price that would 
have been paid without the jump bid.

Let us denote by $j$ the Bidder who has placed a jump bid from a price of $\underline{p}_{j}^{k}$ to $\bar{p}_{j}^{k}$, and denote $t_{i}^{*}$ as the highest type of bidder $i$ that in equilibrium does not match $\bar{p}_{j}^{k}$. The lower bound is then $E\left(v_{i} \mid t_{i}^{*}, t_{j}=t_{i}^{*}, H\left(\underline{p}_{j}^{k}\right), d_{r}\left(\bar{p}_{j}^{k}\right)=\left(\underline{p}_{j}^{k}, \bar{p}_{j}^{k}\right), \forall r: d_{r}\left(\underline{p}_{j}^{k}\right)=\underline{p}_{j}^{k}\right)$. Conversely, note that in the same scenario the expected price paid by the winner if the jump bid is not placed is instead $E\left(v_{i} \mid t_{i}^{* *}, t_{j}=t_{i}^{* *}, H\left(\underline{p}_{j}^{k}\right), d_{r}\left(\bar{p}_{j}^{k}\right)=\left(\underline{p}_{j}^{k}, \bar{p}_{j}^{k}\right), \forall r: d_{r}\left(\underline{p}_{j}^{k}\right) \underline{p}_{j}^{k}\right)$, for some $t^{* *} \leq t^{*}$. 


\section{References}

AverY, C. (1998): "Strategic Jump Bidding in English Auctions," The Review of Economic Studies, 65, 185-210.

Bajari, P., and A. Hortascu (2003): "The Winner's Curse, Reserve Prices and Endogenous Entry : Empirical Insights from Ebay," The Rand Journal of Economics, 34, 329-355.

Bernhardt, D., And D. Scoones (1993): "Promotion, Turnover and Preemptive Wage Offers," American Economic Review, 83, 771-791.

Bhattacharyya (1992): "The Analytics of Takeover Bidding: Initial Bids and their Premia," working paper.

Cassady, R. (1967): Auctions and Auctioneering. University of California Press, Berkeley and Los Angeles, California.

Compte, O., And P. Jehiel (2004a): "The Wait and See Option in Ascending Price Auctions," Journal of the European Economic Association, 2(2), 494-503.

(2004b): "The Wait-and-See Option in Ascending Price Auctions," Journal of the European Economic Association, 2, 494-503.

(2007): "Auction and Information Acquisition: Sealed Bid or Dynamic Formats," The RAND Journal of Economics, 38(2), 355-372.

Cramton, P. (1997): "The FCC spectrum auctions: An early assessment," Journal of Economics and Management Strategy, 6(3), 431-495.

Fishman, M. J. (1988): "A Theory of Preemptive Takeover Bidding," The RAND Journal of Economics, 19, 88-101.

Hernando-Veciana, A., And F. Michelucci (2011): "Second Best Efficiency and the English Auction," Games and Economic Behavior, 73(2), 496-506. 
Hirshleifer, D., AND I. PNG (1989): "Facilitation of Competing Bids and the Price of a Takeover Target," The Review of Financial Studies, 2-4, 587-606.

Michelucci, F. (2012): "Information Acquisition and Jump Bidding with Private and Common Values," work in progress.

Ockenfels, A., And A. E. Roth (2002): "The Timing of Bids in Internet Auctions : Market Design, Bidder Behavior and Artificial Agents," Al Magazine, 23, 79-88.

(2006): "Late and Multiple Bidding in Second-Price Internet Auctions : Theory and Evidence Concerning Different Rules for Ending an Auction," Games and Economic Behavior, 55(2), 297-320. 


\section{Working Paper Series}

ISSN 1211-3298

Registration No. (Ministry of Culture): E 19443

Individual researchers, as well as the on-line and printed versions of the CERGE-EI Working Papers (including their dissemination) were supported from institutional support RVO 67985998 from Economics Institute of the ASCR, v. v. i.

Specific research support and/or other grants the researchers/publications benefited from are acknowledged at the beginning of the Paper.

(c) David Ettinger and Fabio Michelucci, 2012

All rights reserved. No part of this publication may be reproduced, stored in a retrieval system or transmitted in any form or by any means, electronic, mechanical or photocopying, recording, or otherwise without the prior permission of the publisher.

Published by

Charles University in Prague, Center for Economic Research and Graduate Education (CERGE) and

Economics Institute ASCR, v. v. i. (EI)

CERGE-El, Politických vězňů 7, 11121 Prague 1, tel.: +420 224005 153, Czech Republic.

Printed by CERGE-EI, Prague

Subscription: CERGE-EI homepage: http://www.cerge-ei.cz

Phone: + 420224005153

Email: office@cerge-ei.cz

Web: http://www.cerge-ei.cz

Editor: Michal Kejak

The paper is available online at http://www.cerge-ei.cz/publications/working_papers/.

ISBN 978-80-7343-273-7 (Univerzita Karlova. Centrum pro ekonomický výzkum a doktorské studium)

ISBN 978-80-7344-265-1 (Národohospodářský ústav AV ČR, v. v. i.) 
CERGE-EI

P.O.BOX 882

Politických vězňů 7

11121 Praha 1

Czech Republic http://www.cerge-ei.cz 